\title{
Urban and Regional Planning Strategies to Achieve Sustainable Urban Development: (Subject review)
}

\author{
Ali Abdul Samea Hameed \\ Lecture \\ Governmental Contracts Division \\ University of Baghdad, Baghdad \\ Iraq
}

\begin{abstract}
Sustainable urban planning provides cities with the ability to combat climate change. Integrated urban hubs built to put together residents, events, houses, and green facilities, with convenient walking and cycling connections between them and an almost excellent bus service to the rest of the area. This ensures that everyone has equal access to benefits and facilities with the lowest financial and environmental prices with the most productive and healthy combination of transport types, and with the highest tolerance with damaging occurrences. For long-term sustainability, peace shared prosperity and prosperous, democratic society, inclusive growth is critical. Ideally, communities can create strategies to protect the natural habitat of land use as best as they can. Public developments with multiple bike paths and footpaths parallel to green fields and roads that integrate natural habitats are more effective planning initiatives, increasing the attractiveness and feasibility of mobility alternative steps. Stadt proposals for green parks, wide sidewalks and car-free zones at the city centers would also implement walkable street policies. In integrated development, reduction in urban sprawl has been a critical priority. In terms of geography, bringing the jobs, family and shopping as similar as possible was important. Urban planning, in conjunction with vehicle paths, would rely on omnipresent links both to the public transport and the pedestrian route; therefore, in addition to organized mass transportation, effective modes of travel do not necessarily require automobiles (walking, cycling) remain an option. The optimal city would be exceptionally densely situated, with a variety of environmentally sustainable transit options.
\end{abstract}

Key Words: Sustainable Urbanization, Sustainable Urban Development Strategies, Urban Development.

\section{INTRODUCTION}

The more traditional concepts of urban planning cover social concerns and priorities for community sustainability, wildlife habitat protection, open spaces, and attempts to address urban environmental problems [1,2]. Modern community development is formulated more with the business level plan in which of the assorted dimensions are there with sustainable development [3].

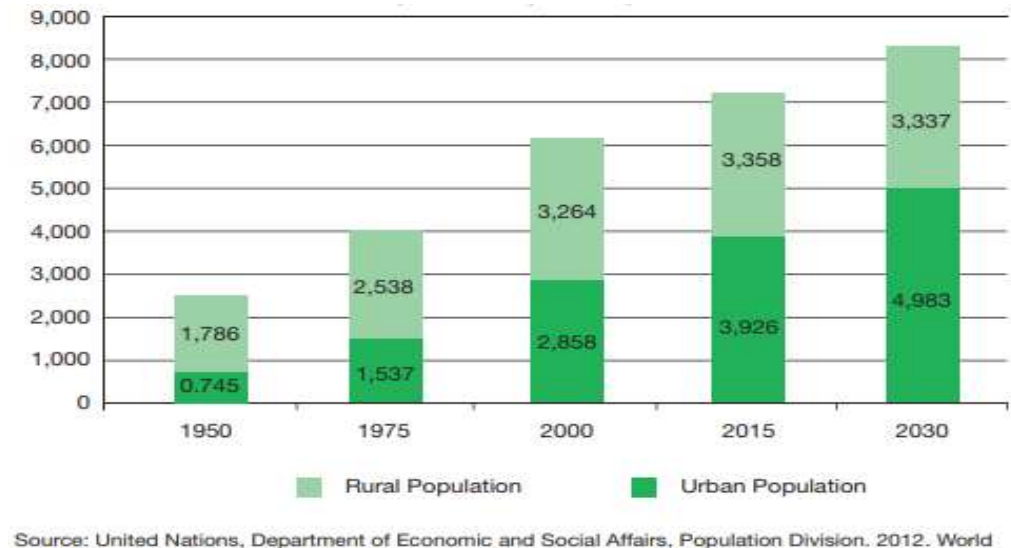

Urbanization Prospects: 2011 Revision, CD-AOM.

Figure 1: Predicted Growth of Urban and Rural Population 1950-2030 (Billions of Persons) 
Community public transport is a valuable way of demonstrating tax growth in the process of urban planning. Areas in a metropolitan area built strongly with access to mass transport have growing opportunities for business growth. A smart town integrates smart public transit into urban development, solving natural, social and economic issues [4]. The best new development plans build rapid transit through areas providing strong jobs potential; building vibrant metropolitan centers with job creation, economic prosperity and a healthy local economy [5].

Prioritizing efficient rapid transportation in community development for both inner cities and suburbs further solves social justice issues; by improving the economies of communities regardless of the socioeconomic background of the region's citizens [6]. Urban planning constructs in the realms of infrastructure, architecture and social and political elements. Urban planning is, in many aspects, a professional profession, an undertaking involving political pressure and civic engagement, and an intellectual discipline. The framework also encompasses priorities, data collection and analysis, modelling, planning, innovative studies and audience interaction [7].

The urban planning method includes the fields of engineering and architecture, as in transport and development. Ideally, the green building of a town that wants to become a sustainable urban area, especially building practices, upgrades existing buildings to a high level of energy efficiency, and sustainable transport, particularly electricity $[8,9]$, should be given priority. It is necessary to expose the political and social incentive to improve growth concepts before these modes of action can be adopted.

The development of environmental ideas and the formation of consciousness amongst people is a priority for education and knowledge. The maps of GIS are the ubiquitous methods of modern urban planning .. GIS maps are used in strategic planning to generate visualizations and forecasts to simplify and resolve environmental, economic and social issues based on several urban planning development choices.

Asia is increasingly being urbanized, and even though it was mainly rural in 1950 with just $17 \%$ of its 1.4 billion inhabitants in towns or villages, new figures from the UN (2004) show that 55\% of Asians - 2,7 billion people - will be living in urban regions by mid-2022. As a consequence, almost half the population growth in Asia in urban areas will occur in 2015. However, increased suburban growth poses significant challenges to quality of life, such as growing inequality and violence [10, 11]. The local and global climate is considerably affected. Asia also features some of the world's most developed cities, with greenhouse gas (GHG) at the highest rate.

Many of the unique aspects of Asia's urbanization also exacerbate environmental issues. Despite these issues, there is reason to believe that urbanization would continue to offset the climate's degradation. Globally, municipalities barely occupy $2 \%$ of the world's gross land area but make up $75 \%$ of all capital used. Since waste production is approximately in line with resource use, an equal share of total waste, including air emissions, toxic effluents and solid waste, is inevitably the obligation of manufacturing areas. In urban areas alone, nearly $80 \%$ of gross global emissions is due to GHG contaminants, including carbon dioxide, methane and nitrogen oxide [12].

This statistic's environmental ramifications are that urban areas play a significant role in climate change, mainly as air pollution's ramifications are discussed with loss of land and vegetation cover associated with urbanization. Given the above, the unchecked population's environmental impacts are predicted to be devastating over the long term in developing countries (Pearce 2006). The outcome on this scale would lead to high economic costs, such as the sum of gross domestic product (GDP) in a country, by fair calculation.

In comparison, air pollution alone lowers a nation's annual GDP by an average of $2 \%-4 \%$ or more for certain nations. In the People's Republic of China (PRC), the economic cost of deaths and diseases in urban areas is nearly 5\% of the gross domestic product. These results are not confined to advanced countries. Research by the World Health Organization consisting of Austria, France and Switzerland showed that traffic-only mental health costs were roughly equal to 1.7 percent of GDP, which is slightly more significant than the costs of care for traffic injuries (CNN 2000) [13].

Similarly, an annual total environmental pollution pressure of at least \$ 1 billion for the 12 million inhabitants of Canada's Ontario Province is taken into account by patient residents, trips to hospitals, and occupational absenteeism (OMA 2000). These figures put an annual cost of well over one billion dollars on air and water pollution in Jakarta, Indonesia, with \$2 billion for Bangkok, Thailand. Inevitably, Asia has been increasingly urbanized at a significant environmental expense, and this has been hit disproportionately by young people, the most marginalized urban population group, and the deteriorating climate sustainability[14]. 
With that, global development has also increased living conditions in Asia's urban areas and pulled millions out of misery. In the long term, sustaining sustainable development in Asia's metropolitan areas would entail accelerated economic progress leading to significant rises in living standards while mitigating the environmental harm associated with this development at the same time [15]. This will include, in particular, addressing both waste arising from the growth, use, and delivery of services in urban environments, as well as the disastrous effects that such waste generation entails on climate change.

There have not been any encouraging impacts of particular measures to mitigate waste generated by rapid population growth. Initiatives such as the promotion of sustainable burning of coal, the substitution of natural gas with other liquids, public transport, and policies encouraging sustainable behavior [16]. Equally alarming are the results of polluter charges or taxes and control initiatives, such as laws intended to limit polluting practices. The results of both the power and other pollutant management measures were quite disappointing in this regard [17].

This will, however, ultimately result in green land, air- and water pollution and GHG emissions are increased, thereby improving Asian cities' livelihoods. Given the shortcomings of the above initiatives, better scheduling and technological advancement should be the primary means of achieving this planned transformation and reducing fossil fuels' need substantially while maintaining their quality of life. Finally, such changes would demand that this portion of policymakers change their emphasis from economic development to quality of life.

Green Cities Transportation clearly describes facilities as transparency, privacy, eco-friendliness and low cost. Together, these features reflect multiple facets of sustainable development as Asia's fast economic growth contributes to incentives for a substantial proportion of vehicle emissions, which are a significant contributor to GHG pollution driving global climate change. Oil-based fuels dominate the energy transportation market. As Asia is supposed to mitigate the most significant GHG emission shifts, a crucial element in countering anthropogenic global warming is tackling the region's increase in automotive emissions pollution.

As the quantity of fossil fuels consumed by vehicles is directly related to the number of automotive emissions, future urban mobility indicates the rise in car gas emissions, such as low-carbon transport networks, expanded use of unmotorized transport, integrated urban transit policies and tr, could be significantly smaller.

Examples include models of transport using less energy and fewer emissions and increasing the efficiency of existing modes of transport. Another practical approach to improving the future transport infrastructure's performance is introducing emerging technologies into the design of transport systems and operation to build intelligent transport networks.

Water Supply Cities track the past municipal strategies for water resources focused on wastewater treatment, sanitation and increase water safety. The benefits of creating water-sensitive societies are illustrated; water resilience is critical for biodiversity and demonstrates what is essential to make urban environments water-sensitive based on numerous examples of initiatives introduced in Asian cities and international best practice. The chapter provides a range of specific examples of technologies available for water-smart communities [19] in illustrating water conservation infrastructures such as advanced water drainage systems, rainwater harvesting and wastewater treatment.

The Solid Waste Management method used by Asian cities usually represented the degree of technical abilities, resources and environmental knowledge in each area, according to Reynar Rollan. Solid Waste Management. This results in a significant disparity between the parameters used and the degree of environmental conservation obtained by the low-income urban centers and populations in the developed world. Many components of Green City, solid waste management systems, have been introduced in most Asian cities. Also, a regulatory framework for the efficient management of solid waste was developed in most Asian countries at the turn of the 21 st century.

Furthermore, numerous municipalities have launched initiatives for environmental education in all facets of society. These policies establish an urban sustainability-related waste disposal mechanism. Such a community acknowledges the implications for the economic growth of diminishing wealth and resources, and the reduced use of recycled materials leads to poor health and environmental circumstances. Furthermore, popular awareness of these factors allows legislatures, organizations, the private sector, and people to work together to fulfil the goals of initiatives for solid waste management [20]. 


\section{SUSTAINABLE URBAN DEVELOPMENT}

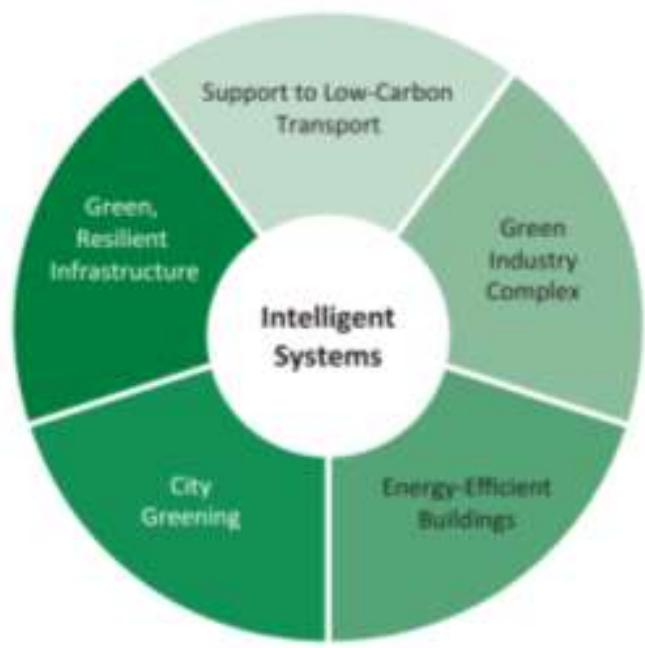

Souroe: Avian Development Bark:

Figure 2: Investment Dimensions for Green Sustainable Urban Development

\subsection{Low-Carbon Transport}

The scale, location, and shape of the land development are influenced by an important but not yet used method for creating sustainable cities and how the public transport system is included in those land use parameters. Given that economic capital is often guided to areas where physical connectivity is more superficial, the architecture and preparation of transport networks have significant implications for urbanization's spatial distortion. That refers to water, sanitation, infrastructure and homes as well. Urban policymakers surprisingly rarely use this powerful method to regulate development.

It was more successful where all segments of society, such as local and national governments, capital project division, private ownership, and the public, were involved in the planning phase. The development priority will be on those areas where development is required, both artery and secondary road networks. Construction and activity standards that apply to prospective occupants' desires and strategies, namely low-income communities, should be devised. Early in the global building sector, a robust and environmentally sustainable mass transportation system would be built without responding to the resulting displacement.

\subsection{Green Industry}

One solution for addressing industrial waste processing problems is to turn one company by-product into another's supplies. The Circle Economy (CE) and Japan's "eco-cities" have taken advantage of this policy. CE waste management strategy has been effectively applied, requiring both engagements by the government and well-planted institutional structures. Although the CE approach to waste management entails some increased costs, many CE approaches are economically helpful over the long run, mainly because of the risks of environmental harm avoided [21].

\subsection{Buildings with Energy-Efficient Perspectives}

The decreasing cost of solar panels will make buildings utterly self-sufficient in electricity. This is particularly true once the usage of these technologies and techniques, which can cut energy consumption by 60 percent or more, is a hypothesis. When applied at domestic and local levels, incentives to create energy-efficient buildings and encourage energy-saving activities are substantial. In addition to the energy conservation measures for transport and land use mentioned above, cities can minimize electricity at residential and even individual levels by planning accordingly.

By redefining appropriate fire laws, utility fees and property taxes, most other incentives to encourage these significant changes can be identified. Local standards can be used to achieve pace at environmental-compatible speeds and promote the use of natural light, harvesting rainwater, and green energy types. They can also be used to fix drainage problems before they arise. In many Asian jurisdictions, construction regulations concentrate on nature, physical and social settings that differ significantly from Asia. 


\subsection{City Greening in Abu Dhabi}

It is a significant issue in designing and implementing a cooling model of urban settings as wind speed effect temperature, evaporative cooling rates and plant transpiration. A good temperature-controlled designed atmosphere facilitates ventilation and thus carbon loads and air emissions arising from coal usage. Add gardens, green roofs, and water sources into urban landscape planning enhance the cooling impact of wind and contribute to much lower carbon usage rates and, therefore, air emissions. This strategy to enable natural air ventilation, fresh air supply and microclimatic protection to be used was significantly incorporated into Abu Dhabi's Masdar development

\subsection{Urban and Regional Planning Strategies}

City councils play a pre-eminent position as the culture moves toward greater sustainability. They are creating a world people stay and work. Online communication occurs here, urban infrastructures are being operated, and city planning and architects visions are being developed. The urbanization of the population becomes inevitable as the population rises. Urbanization contributes to a more significant environmental impact; cities' 'ecological footprint' is growing. Sustainable development requires improving how urban cities carry out their operations, such as water utilization and people and products activities [22].

Sustainable growth has been described as an advancement that satisfies present needs without compromising the future capacity to meet their own needs. Therefore, sustainable urban planning means a mechanism by which prosperity can be accomplished, with focus on growth, success, and progressive change.

Sustainable urban planning highlights the need to change business processes to meet sustainability targets and the harmony of social and economic concerns. Sustainability needs to be tackled on a regional basis and changes.

Sustainable urban planning highlights the need to change business processes to meet sustainability targets and the harmony of social and economic concerns. Sustainability needs to be tackled on a regional basis, and changes need to focus on urban ecosystem engagement with the national economy and climate.

\section{CONCLUSION}

Governments are having a role in controlling patterns of urban spatial growth and land development through infrastructure, taxes, and land-use rules. Sometimes, however, regulation is not the primary force; more, the real estate industry influences investments and determines patterns. Notwithstanding that, the government will also either promote consolidation or sprawl or oppose it. These choices are backed up by strategic decisions concerning transportation networks or the development of ring roads. These strategic choices are preferably backed by legislation that defines Floor Space Indexes (FSI) or urban areas. Business structures have proven more rigorous than permits in terms of a higher land area, considering location and proximity considerations. However, the government's economic development tends to influence the urban spatial structure and the property market. While legislation regulating companies will lead to community planning and zoning, many of these policies do not have the desired impact. Besides, the bill will implement sustainable development.

\section{REFERENCES}

[1] Yu, H., Song, Y., Chang, X., Gao, H., \& Peng, J. (2018). A Scheme for a sustainable urban water environmental system during the urbanization process in China. Engineering, 4(2), 190-193.

[2] Wai, K. M., Wang, X. M., Lin, T. H., Wong, M. S., Zeng, S. K., He, N., ... \& Wang, D. H. (2017). Observational evidence of a long-term increase in precipitation due to urbanization effects and its implications for sustainable urban living. Science of the total environment, 599, 647-654.

[3] Vasenev, V. I., Dovletyarova, E. A., Plyushchikov, V. G., \& Valentini, R. (2016). Megacities 2050: from urbanization threats to sustainable urban development. Вестник Российского университета дружбы народов. Серия: Агрономия и животноводство, (4).

[4] Kazak, J. K. (2018). The use of a decision support system for sustainable urbanization and thermal comfort in adaptation to climate change actions-The case of the Wrocław larger urban zone (Poland). Sustainability, 10(4), 1083.

[5] ABE, R., \& Kato, H. (2017). Built environment, travel, and residential satisfaction in a developing city: can residents under rapid urbanization agree with a sustainable urban form?. Asian Transport Studies, 4(3), 481-498. 
[6] Currie, P. K., \& Musango, J. K. (2017). African urbanization: assimilating urban metabolism into sustainability discourse and practice. Journal of Industrial Ecology, 21(5), 1262-1276.

[7] Shen, L., Shuai, C., Jiao, L., Tan, Y., \& Song, X. (2016). A global perspective on the sustainable performance of urbanization. Sustainability, 8(8), 783.

[8] Li, Y., Jia, L., Wu, W., Yan, J., \& Liu, Y. (2018). Urbanization for rural sustainability-Rethinking China's urbanization strategy. Journal of Cleaner Production, 178, 580-586.

[9] Cui, X., Fang, C., Liu, H., \& Liu, X. (2019). Assessing sustainability of urbanization by a coordinated development index for an Urbanization-Resources-Environment complex system: A case study of Jing-Jin-Ji region, China. Ecological Indicators, 96, 383-391.

[10] Shannon, M., Otsuki, K., Zoomers, A., \& Kaag, M. (2018). Sustainable Urbanization on Occupied Land? The politics of infrastructure development and resettlement in Beira city, Mozambique. Sustainability, 10(9), 3123.

[11] Burt, J. A., \& Bartholomew, A. (2019). Towards more sustainable coastal development in the Arabian Gulf: Opportunities for ecological engineering in an urbanized seascape. Marine pollution bulletin, 142, 93-102.

[12] Chai, B., \& Seto, K. C. (2019). Conceptualizing and characterizing micro-urbanization: A new perspective applied to Africa. Landscape and Urban Planning, 190, 103595.

[13] Shahidehpour, M., Li, Z., \& Ganji, M. (2018). Smart cities for a sustainable urbanization: Illuminating the need for establishing smart urban infrastructures. IEEE Electrification Magazine, 6(2), 16-33.

[14] Lin, X., Lu, C., Song, K., Su, Y., Lei, Y., Zhong, L., \& Gao, Y. (2020). Analysis of Coupling Coordination Variance between Urbanization Quality and Eco-Environment Pressure: A Case Study of the West Taiwan Strait Urban Agglomeration, China. Sustainability, 12(7), 2643.

[15] Ismail, M. A., Ludin, A. N. M., \& Hosni, N. (2020, July). Implementing Sustainable Urbanization Development Using Geospatial Approach. In IOP Conference Series: Earth and Environmental Science (Vol. 540, No. 1, p. 012044). IOP Publishing.

[16] Zhang, Y., Su, Z., Li, G., Zhuo, Y., \& Xu, Z. (2018). Spatial-temporal evolution of sustainable urbanization development: A perspective of the coupling coordination development based on population, industry, and built-up land spatial agglomeration. Sustainability, 10(6), 1766.

[17] Butsch, C., Kumar, S., Wagner, P. D., Kroll, M., Kantakumar, L. N., Bharucha, E., ... \& Kraas, F. (2017). Growing 'smart'? Urbanization processes in the Pune urban agglomeration. Sustainability, 9(12), 2335.

[18] Cartalis, C., Santamouris, M., Nyktarakis, G., Polydoros, A., \& Th, M. (2016). Assessing the interlinks between urbanization, the built environment and the thermal environment in view of smart and sustainable urban development: a demonstration application for Athens. International Journal of Earth \& Environmental Sciences, 2016.

[19] Basiri, M., Azim, A. Z., \& Farrokhi, M. (2017). Smart city solution for sustainable urban development. European Journal of Sustainable Development, 6(1), 71-71.

[20] Liu, Y., Zeng, C., Cui, H., \& Song, Y. (2018). Sustainable land urbanization and ecological carrying capacity: A spatially explicit perspective. Sustainability, 10(9), 3070.

[21] Wei, J., Qian, J., Tao, Y., Hu, F., \& Ou, W. (2018). Evaluating spatial priority of urban green infrastructure for urban sustainability in areas of rapid urbanization: A case study of Pukou in China. Sustainability, 10(2), 327.

[22] Zeng, C., Deng, X., Dong, J., \& Hu, P. (2016). Urbanization and sustainability: comparison of the processes in "BIC" countries. Sustainability, 8(4), 400. 